\title{
Socialização docente e experiências pré-profissionais
}

Teacher Socialization and pre-professional experience

\author{
Daniela de Moura Clates \\ Universidade Federal de Santa Maria, Brasil \\ danielaclates@yahoo.com.br \\ Carolina Nascimento Leäes \\ Universidade Federal de Santa Maria, Brasil \\ cnleaes1990@gmail.com
}

Maria Cecilia da Silva Camargo

Universidade Federal de Santa Maria, Brasil

mceciliacg6@hotmail.com

Andressa Aita Ivo

Universidade Federal de Santa Maria, Argentina

dessaaita@gmail.com

\section{Resumo:}

Este estudo, de caráter descritivo, teve como objetivo analisar as diferentes experiências acumuladas ao longo do período da graduação e sua repercussão sobre o processo de iniciação à docência escolar. Foram usados relatos biográficos de seis egressos do curso de Licenciatura em Educação Física da Universidade Federal de Santa Maria com, no máximo, três anos de docência. Inicialmente, os jovens professores consolidam seu habitus profissional dentro do campo escolar. Nesse espaço ocorrem relações desiguais por disputa de reconhecimento, cabendo aos novatos adequarem-se às situações já impostas ou buscar estratégias para mudar a realidade encontrada podendo, em algumas situações, valer-se de experiências e aprendizagens do período estudantil, muitas vezes possibilitadas pela participação em diferentes espaços formativos paralelos ao currículo (projetos de ensino/pesquisa/ extensão, movimento estudantil).

PalaVras-CHaVE: Experiências, Formação inicial, Habitus, Socialização docente.

\section{Abstract:}

This descriptive study aims to analyse the different experiences accumulated over the graduation period and their impact on the process of initiation into schooling. Biographical accounts of six graduates of a Bachelor of Physical Education of Santa Maria University were used, with a maximum of three years of teaching. The study shows that young teachers create professional habitus on campus. In this space, unequal relationships take place caused by recognition dispute. Thus, newcomers will have to adapt to those situations already imposed or seek strategies to change that reality. In some situations, they can make use of the experiences and learnings from their student days; this is often made possible by their participation in different formative spaces parallel to the curriculum (teaching / research / extension projects, student movement).

KEYWORDS: Experiences, Initial training, Habitus, Teacher socialization.

\section{INTRODUÇÃO}

O percurso formativo pode ser definido como um processo longo que abarca uma ampla variedade de saberes, compreendidos à luz de Tardif (2002) como um conjunto de conhecimentos, competências, habilidades (ou aptidóes) e atitudes. Tais saberes começam a se desenvolver ainda na formação escolar, 
podendo alterar-se durante a formação inicial, legitimam-se no início da profissão, nos primeiros anos da carreira, e continuam a se desenvolver durante a vida profissional do docente.

Tardif (2002) e Borges (2004) convergem no entendimento de que a formação tem privilegiado os conhecimentos disciplinares com pouca conexão com a ação profissional. São esses conhecimentos, no entanto, que são aplicados na prática, nos estágios e em outras atividades. Há, portanto, uma relação de distância entre o currículo e o campo de atuação profissional e que se agrava pelo trato fragmentado dado aos conhecimentos presentes na formação acadêmica. Decorrente desse processo, as disciplinas previstas no curso adquirem pouco significado para os acadêmicos e lhes parecem desprovidas de sentido para sua futura atuação na escola.

Em estudo realizado por Lago (2011) a autora revela que:

[...] os futuros professores necessitam conhecer o mais cedo possível as situações e os sujeitos com os quais irão trabalhar. Significa se apropriar da prática profissional como instancia permanente e sistemática na aprendizagem do futuro profissional. Para tanto os projetos de extensão surgem como complemento no currículo do acadêmico dando-lhes subsídios e consequentemente maior compressão de suas responsabilidades profissionais. (Lago, 2011, p.15)

Não só os projetos de extensão, como cita a autora, como também os projetos de pesquisa e ensino, exercem um papel importante na formação dos futuros professores, contribuindo na atuação profissional dos mesmos. No sentido de aproximar os conhecimentos com a realidade que os mesmos irão encontrar nas escolas, quando ingressarem no mundo do trabalho, assumindo sua condição de professor.

A constatação de que o currículo não atende às suas expectativas leva os acadêmicos a inserir-se em grupos e projetos de pesquisa e extensão, na tentativa de ampliar seus conhecimentos e experiências na área de estudo desejada, agregando novos significados à sua formação inicial. A partir dessa constatação, estabelecemos como objetivo de investigação analisar de que modo as diferentes experiências de participação em atividades de pesquisa, ensino e extensão, acumuladas ao longo da graduação, repercutem sobre o processo de iniciação à docência dos egressos do curso de Licenciatura do Centro de Educação Física e Desportos da Universidade Federal de Santa Maria (CEFD/UFSM), Santa Maria, Rio Grande do Sul, Brasil.

\section{Metodologia}

A presente pesquisa é de natureza qualitativa, destacando seu caráter descritivo, enfatizando a importância do processo e superando uma ênfase restrita aos resultados e produto final (Triviños, 1987). Assim, o processo investigativo configurou-se como estudo de caso, visando aprofundar a descrição de determinada realidade (Idem, Ibd.). Adotamos a entrevista biográfica como instrumento da investigação, por permitir aos participantes retomarem a trajetória formativa por meio de um processo reflexivo.

Nesta pesquisa tivemos como colaboradores ${ }^{1}$ seis professores egressos do CEFD//UFSM, atuantes na rede pública de ensino e cujo ingresso na carreira não ultrapassa três anos. Todos continuam em processo de formação continuada, sendo que três colaboradores realizam mestrado e os outros três cursam especialização.

Foram utilizadas entrevistas semi-estruturadas cujo caráter dialógico, propicia que os envolvidos (entrevistado e entrevistador) cheguem à elaboração de um conhecimento que expresse uma realidade pessoal e coletiva (Triviños, 1987). Para Poupart (2012), trata-se de uma opção que permite captar a perspectiva dos investigados, relevantes à compreensão das condutas sociais e conduz à um conhecimento da realidade investigada, tomando a experiência dos investigados como fonte privilegiada de informação.

As entrevistas biográficas permitiram aos egressos, segundo Bolívar (2002, p.178):

Refletir sobre experiências significativas (quer se trate de experiências formativas ou de incidentes críticos pessoais ou profissionais) pode possibilitar assumi-las, controla-las como práticas do passado que chegaram a constituir-se em hábitos e ao mesmo tempo revelar dimensões que devam ser mudadas. 
Pode-se dizer que ao decorrer da entrevista o indivíduo analisa sua trajetória, trazendo à tona elementos que foram significativos para sua formação e outros não, refazendo seu percurso. Nessa perspectiva, Molina e Molina Neto (2010, p.168) argumentam que

Produzir narrativas de nossas experiências nos faz viver um processo profundamente pedagógico, no qual nossa condição existencial é o ponto de partida para a construção do nosso desempenho presente e futuro. É por meio do exercício da narrativa que podemos identificar, organizar e nomear os significados que atribuímos a inúmeros fatos que vivemos mediante os quais podemos reconstruir as diversas compreensões que temos sobre nós mesmos. É um valioso instrumento para qualificar nossas reflexóes de modo contextualizado e, como resultado, temos a possibilidade de ressignificar o vivido.

Na mesma direção, Moita (2007) destaca a importância dessa abordagem para que haja uma compreensão das múltiplas interações que acontecem ao longo da vida, captando-as de modo global e dinâmico. Para a autora, a história de vida possibilita "captar o modo como cada pessoa, permanecendo ela própria, se transforma”, considerando-se toda sua existência (Moita, 2007, p.116).

$\mathrm{O}$ processo de análise consistiu-se de sucessivas leituras, visando extrair unidades temáticas que expressassem aspectos mais significativos e potentes das narrativas. Mediante esse conjunto de unidades temáticas, foi feito um exercício de aproximação e agrupamento que indicassem categorias balizadoras para a elaboração de análises e interpretações mais consistentes, por meio de triangulação com a literatura que fundamenta o estudo. Resultou desse processo, a emergência de três categorias, as quais dão título às seções a elas correspondentes.

\section{EXPERIÊNCIAS FORMADORAS: PERÍODO DE GRADUAÇÃo E SOCIALIZAÇÃo DOCENTE INICIAL}

O período que compreende a licenciatura costuma ser denominado como de formação inicial, mesmo quando se trabalha com o conceito de percurso formativo, o qual expressa uma visão processual da formação, cujas raízes se encontram na escolarização e se prolonga durante a carreira docente (grifos nossos). Tal denominação demarca a centralidade desse período que, espera-se, possa assegurar o acesso e elaboração de conhecimentos científicos, pedagógicoæ técnico-instrumentais necessários à futura atuação docente (Carreiro da Costa, 1996).

Ao término do curso, o campo de atuação dos licenciados costuma ser a escola onde, a partir desse momento, buscam conquistar seu espaço. Dentro do campo escolar o novato encontrará um ambiente no qual as relações já estão estabelecidas. Bourdieu (1996) descreve o espaço social como um campo que é tanto um campo de forças quanto um campo de lutas, no qual os agentes neles inseridos se confrontam, ainda que fazendo "com meios e fins diferenciados conforme sua posição na estrutura do campo de forças, contribuindo assim para a conservação ou a transformação da estrutura” (p.50). Há então uma hierarquia no campo escolar, onde ocorrem lutas e disputas por postos e espaços; cujo tensionamento de forças, levam ao reconhecimento de algumas vozes e ao silenciamento de outras.

É no interior do campo escolar que se constitui a socialização docente, na qual o professor é objeto e sujeito, sendo um agente social. Nessa perspectiva, os professores mais antigos, teriam um capital de conhecimentos maior que os iniciantes, por estarem há mais tempo no campo escolar. Esse conhecimento pode, em grande medida, estar relacionado a situaçóes de experiências vividas, correspondendo ao que Tardif (2002) denomina de "saberes experienciais". Trata-se de um capital simbólico no qual, o acúmulo de experiência profissional constitui-se em vantagem para os professores mais antigos, mas que não pode ou não precisa ser tomado como elemento definidor de uma relação de subalternidade dos professores ingressantes.

O processo de ingresso na docência costuma ser marcado por um período de adaptação, quando a realidade do cotidiano mostra-se muito mais desafiadora do que esperam os professores recém-formados. Day e Gu (2012) assinalam a falta de apoio na escola, a conduta das turmas e a excessiva carga de trabalho como fatores que têm levado uma parcela de professores a desistirem da carreira ainda em etapa inicial. Para esses autores, 
a carga emocional mobilizada nesse período é intensa e o suporte por parte dos colegas no interior da escola é de fundamental importância.

Na mesma direção, Tardif (2002) define o início da carreira docente (de 1 a 5 anos) como um importante momento, para que os professores acumulem experiência, ou seja, para que possam aprender fazendo, mostrando aos demais e a si mesmo a sua capacidade de ensinar. Durante essa fase, é comum que ocorram enfrentamentos nas relações com os pares e com os saberes produzidos pela experiência coletiva dos professores, forma pela qual os saberes experienciais passam a adquirir mais objetividade.

No exercício profissional os professores encontram variadas situações, e esse processo formador é o que lhes permite desenvolver o habitus, definido por Bourdieu (1983) como um conjunto de referências, códigos e disposições adquiridas, ao longo desse percurso. São crenças duradouras adquiridas no decorrer da vida; porém, como não são permanentes, podem mudar de acordo com as situações encontradas. $\mathrm{O}$ habitus é constituído socialmente, por meio das relações entre os sujeitos envolvidos nesse processo.

Pode-se dizer que existe uma relação direta entre o habitus e a construção da socialização, pois o professor novato vai incorporando experiências geradoras de disposições, que, por sua vez, vão constituindo o habitus professoral (Silva, 2005), que é a base para o saber como agir, de acordo com as situações impostas no dia a dia. Segundo Freitas (2002) a socialização profissional ocorre na articulação entre o agente e o meio profissional ao qual pretende se filiar, sendo importante compreender tanto as estratégias e interações dos agentes quanto o espaço em que esse processo ocorre.

O processo de socialização é contínuo, ou seja, não inicia necessariamente quando os egressos se inserem na escola, na condição de professores. Deve-se levar em consideração sua trajetória e seu percurso formativo, onde as experiências são vastas e as relações entre os pares também.

O período de realização da licenciatura, anterior à vida profissional, situa-se na socialização secundária, de acordo com Silva e Souza Neto (2011). Encontramos, nos resultados apresentados por esses autores, algumas similaridades com nossa investigação, no que diz respeito a relevância de experiências paralelas ao curso de licenciatura como espaços formativos preparatórios para a docência.

Os estágios supervisionados e as atuações em projetos de extensão e pesquisa se enquadram nessas duas situações, e as experiências adquiridas nesses processos, quando vivenciadas no interior da escola, são determinantes para o tornar-se professor. "Assumir a docência 'precocemente' na escola constitui-se numa oportunidade de perceber algumas lacunas da formação inicial” (Bracht e Silva, 2005, p.68), ou seja, pode ser um momento de frustração por parte dos acadêmicos, por perceberem na sua prática docente o distanciamento que existe na relação entre teoria e prática durante a formação inicial, quando muitos conhecimentos são negligenciados, tornando-se necessários buscá-los em espaços para além do currículo formal.

Dentro da perspectiva teórica proposta por Tardif (2002) não é possível discutir o saber sem relacionálo com o trabalho cotidiano dos professores. Através dos saberes e das experiências de vida, os professores forjam sua identidade ${ }^{2}$, por meio de um mecanismo de socialização que pode ser definido ainda por este autor "como um processo de formação do indivíduo que se estende por toda a história de vida através de um percurso que comporta rupturas e continuidades" (p.71).

A prática docente age como um mecanismo de aprendizagem, com o qual os professores reinterpretam sua formação, moldando-se ao seu novo status, utilizando apenas o que é pertinente ao exercício da docência encontrada. Nesse processo, os professores refletem e reformulam seus saberes, no sentido de construir um saber mais amplo, constituído por todos os outros, e que será legitimado pela prática cotidiana. Essas formulações têm lugar no campo escolar, submetidas às relações de força ali presentes, no que tange ao lugar hierárquico, ocupado tanto por professores quanto por componentes curriculares pelos quais são responsáveis. É um processo atravessado por esses fatores, portanto, muito mais complexo do que uma mera elaboração e formulação de conhecimentos a serem agregados às suas práticas docentes. 
Conforme sustenta Gariglio (2015) outro aspecto a considerar, é a existência de diferentes formas de saber-ser, saber-fazer peculiares a cada subgrupo de professores e seus contextos específicos de trabalho (professores de educação infantil, ensino fundamental, ensino médio, educação profissional, de portadores de necessidades especiais e professores dos diferentes campos disciplinares do currículo escolar). Alguns saberes dos professores não são produzidos por eles mesmos ou pelo exercício de seu trabalho, mas provenientes da família, da escola que os formou, de sua cultura; outros estão fortemente enraizados nas universidades, balizados nas experiências pré-profissionais e são incorporados à sua identidade em diferentes momentos da vida. Emergem, portanto, de várias fontes como a formação inicial e continuada, currículo, socialização escolar, experiência na profissão, cultura pessoal e profissional, aprendizagem com os pares e sua história de vida.

Com base nas entrevistas, constatamos nas falas dos egressos a relevância da participação em diferentes espaços formativos durante o curso de licenciatura para o processo de "tornar-se professor". Alguns aspectos mencionados por eles foram: a construção da identidade relacionada às diferentes experiências, a importância de materializar as pesquisas e proposições realizadas pelos grupos (levando esses conhecimentos para escola), trocas de experiências entre os envolvidos, discussões realizadas dentro desses espaços através de leituras prédefinidas de temas relacionados a prática escolar, variedade muito grande de vivências proporcionadas, noções da realidade escolar como um todo e também contribuição no planejamento.

Por outro lado, alguns relatos alertam para o fato dos estágios não terem cumprido um papel significativo durante a curso, confirmando uma falta de articulação com outros componentes do currículo limitando o preparo para a futura atuação docente (Bracht e Silva, 2005, p.74). Destaca-se o relato do entrevistado José:

"[...] até os estágios não deram muita vivência. Nos estágios tu chegava lá, dava a aula e ia embora sabe. Ai a gente vai pra escola, é é tudo totalmente diferente do que a gente estudou aqui nos 4 anos assim”.

A manifestação de José ratifica a distância entre o que é vivido nos estágios e as condições nas quais o professore irá atuar. Nesse sentido, o trabalho do professor transcende o ato da aula e o estágio, de modo geral, restringe-se a um conjunto de aulas a serem cumpridas ("tu chegava lá, dava tua aula e ia embora”), sem assegurar que os acadêmicos vivenciem a rotina da escola na sua totalidade. Os relatos acrescentavam ainda, situações nas quais os acadêmicos-professores apenas continuam a trabalhar o conteúdo que o professor regente da turma estava trabalhando, ou seja, não é um momento em que o sentimento de ser professor é construído, pela falta de autonomia e liberdade de ação por parte do estagiário.

\section{CAMPO ACADÊMICO, CAMPO ESCOLAR E SOCIALIZAÇÃo PROFISSIONAL}

O campo acadêmico e o escolar são fundamentais na constituição da socialização dos professores entrevistados. nesses espaços, a universidade e a escola, que vivenciam as experiências que agregam diuturnamente novos elementos ao "ser professor", tanto na condição de alunos quanto, posteriormente, de licenciandos.

No início do magistério, o valor atribuído aos novatos está aquém do desejado, devido ao seu baixo capital simbólico perante o grupo, por sua pouca experiência. A busca por reconhecimento e prestígio pelos pares, se dá como um jogo, durante o qual o acúmulo de bens simbólicos se expressa perante o grupo como conquista de poder (Bourdieu, 1989).

A professora Joana relata que a fase inicial do ingresso na escola foi bem complicada. Durante esse período, ela se deparou com algumas adversidades, às quais ela não conseguiu se adaptar; tampouco tentou mudar a situação encontrada.

No período de ingresso na escola, as reações e a forma como se inserem no campo escolar variam; alguns professores logo se adaptam ao que está estabelecido, mas outros questionam e tentam mudar a realidade que lhes é imposta. 
"E ai eu cheguei lá e me trouxeram o Projeto Politico Pedagógico (PPP) da escola, me deram o plano da disciplina e eu vi que faltavam algumas coisas, porque lá não é Educação Física nos anos iniciais, é recreação. Porquê que é recreação? Porque tem a questão da uni-docência, e que se configurar como Educação Fisica os professores pedagogos perdem a gratificação da uni-docência, que é $20 \%$ a mais no salário. E aí, no final do ano, quando a gente tinha reunião pra reformulaçáo do PPP, eu disse que eu não trabalhava só recreação nas minhas aulas e que eu gostaria que mudasse o nome no projeto, porque é Educação Física; aí o primeiro choque que eu tive com os outros professores foi esse. Ai teve uma professora que falou: a como nós vamos mudar o nome, se nós vamos perder a nossa uni-docência. E como fazia um mês e pouco que eu tinha chegado lá, eu fiquei quieto e não falei nada. E ai ficou como recreação, mas dai agora eu já estou conseguindo fazer, mudar e vou ter que tentar pensar em algum outro nome agora pro projeto, que não configure como Educação Física, mas que dê uma visão mais geral, não só de recreação, mas uma visão mais geral relacionada à Educação Física." (Entrevista professor Pedro)

A posição adotada pelo professor Pedro pode ser interpretada como uma forma de resistência alternativa ao confronto direto. O professor expressa a opção por se estabelecer naquela escola e, aos poucos, conquistar espaço e legitimidade de seu componente curricular. Sua situação, ainda que possa parecer semelhante à vivida pela professora Joana, parece apresentar algumas "brechas" para o diálogo e a negociação. Não é possível estabelecer regras ou fórmulas para que um professor novato consolide sua posição junto à comunidade escolar na qual atua, mas é possível observar a importância da capacidade de fazer uma leitura do contexto no qual está ingressando que oriente suas ações. Por outro lado, as experiências paralelas ao currículo podem fornecer subsídios relevantes para esse processo de inserção na carreira, particularmente no que concerne às posturas a serem adotadas frente aos pares. O campo escolar, onde o professor tenta conquistar seu espaço, e particularmente a Educação Física, exige uma legitimidade, como componente curricular, conforme argumenta a professora:

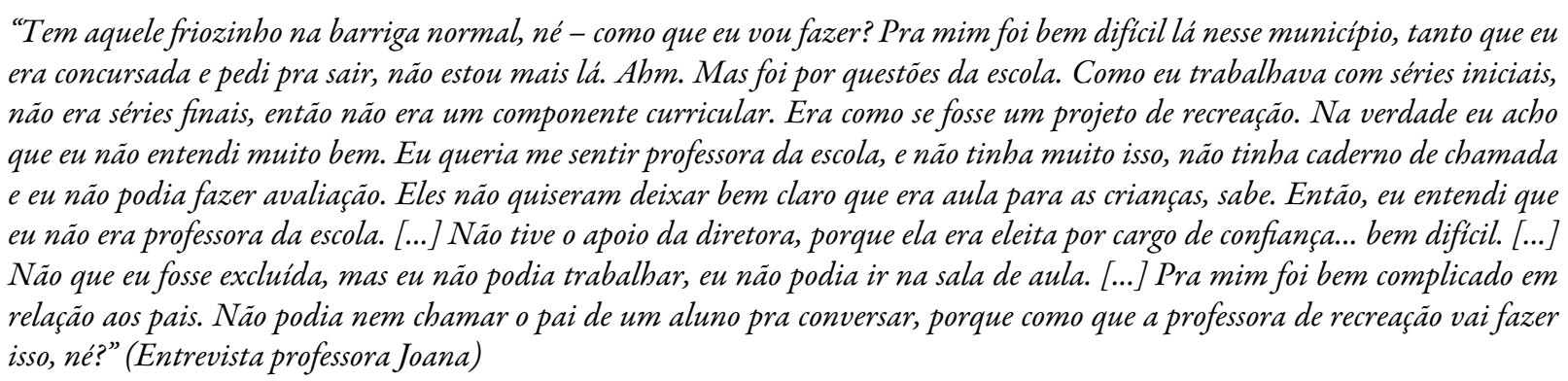

A fala da professora Joana expressa um desprestígio da figura do professor de Educação Física, já que para ela sequer havia caderno de chamada. Este é um dos objetos que configura a existência da disciplina, tanto no que diz respeito ao simbólico quanto ao componente curricular; como ele não existe como tal, Joana não se sentiu exatamente professora, mas talvez uma recreacionista. Embora do ponto de vista legal a existência da disciplina Educação Física esteja prevista como um componente curricular obrigatório Faria, Machado e Bracht (2012, p. 126), sustentam que "essa disciplina apresenta no conjunto da cultura escolar um déficit crônico de legitimidade", conforme os autores "a ausência de reconhecimento do saber mobilizado pelo componente curricular produz nos professores um sentimento de rebaixamento, fazendo com que esses sujeitos se percebam com menor valor na coletividade da escola" (p. 127).

A falta de apoio por parte da direção é outro aspecto apontado pela professora Joana. Nesse momento é que o recém-chegado se depara com a hierarquia existente no campo escolar. Para Araújo, Alves e Cruz (2009, p.36):

Os campos, enquanto espaços estruturados e hierarquizados, são arenas onde são travadas lutas pela conquista de posições e de capital. Sua estrutura envolve lutas e tensões. O capital específico ao campo é desigualmente distribuído e acumulado, o que motiva os agentes que busquem a sua posse na elaboração de estratégias de luta. Os agentes que monopolizam a autoridade específica ao campo tendem a organizar estratégias de conservação, em oposição aos novatos, que detentores de menos capital procuram subverter a dominação, articulando estratégias de subversão. Os momentos de crise são momentos em que através do questionamento das posições dos antigos dominantes, os novatos procuram alterar as posições de poder. 
Apesar de ter se deparado com adversidades no início do processo de docência na escola, a professora Joana não desistiu, e encontrou em outra escola o apoio de que precisava, que fez com que ela se sentisse parte daquele campo, constituindo assim o sentimento de ser professora.

"Agora onde eu estou atuando, que dai sou contratada porque eu sai do concurso, é bem diferente. A equipe diretiva é muito boa, sempre ouvindo os professores. É um componente curricular a Educação Física. Tenho caderno de chamada e faço avaliação. [...] dou a minha aula do jeito que eu quero, com objetivo." (Entrevista professora Joana)

A partir de sua fala, pode-se constatar que, na atual escola, ela vem conquistando seu espaço, sem encontrar maiores dificuldades. Contudo, é preciso considerar a influência que o contexto exerce sobre a atuação docente, ou seja, as boas condições de trabalho nessa escola, e mais o apoio da equipe gestora, contribuíram para que a professora Joana tivesse maior êxito na sua atuação profissional, reforçando as argumentações de Gu e Day (2012) sobre a importância de um ambiente de colaboração no início da docência.

Do mesmo modo, é possível identificar nas falas dos egressos, o quanto sua participação nos projetos de extensão, grupos de pesquisa, ensino, movimento estudantil, etc.; foram importantes para qualificar sua formação. Percebe-se que a inserção nesses espaços extracurriculares ameniza o "choque com a realidade", definição dada pelos entrevistados no momento da entrada na carreira docente, como aponta o seguinte depoimento:

"Eu diria que foi bom. Porque as experiências, principalmente as que eu tive no Programa Institucional de Bolsa de Iniciação à Docência (PIBID) né. Por quêe? Porque elas me deram esse subsidio da realidade, pra enfrentar os problemas. A gente conheceu através do PIBID na escola onde a gente atuou, como ela funcionava. Então, foi mais fácil pra mim, me inserir no contexto da escola aonde eu estou atuando atualmente." (Entrevista professora Paula)

A professora Marta demonstra em sua fala que o processo de iniciação da docência foi muito bom, que a adaptação foi rápida, assim como a aceitação e reconhecimento dos alunos em relação a ela.

"Ainda o processo é algo que tá sendo muito bom. Além de ensinar, eu estou aprendendo muito com eles. É uma coisa assim, sabe, impressionante. E algumas coisas interessantes aconteceram, por exemplo, coisas simples, mas sei lá, acho que faz a diferença. Por exemplo, a primeira turma que eu dei aula, uma semana depois, eles me escolheram pra conselheira da turma. Imagina, eu fiquei superfeliz." (Entrevista professora Marta)

Observa-se na fala do professor Júlio, que ele precisou conquistar seu espaço também em relação aos seus alunos, pelo fato de trabalhar com a Educação de Jovens e Adultos (EJA), e ser bem mais jovem que a maioria dos seus alunos. E como contraponto, tinha também alunos mais jovens, mediante os quais teve que se impor e mostrar sua autoridade como professor, apesar da idade. A relação professor-aluno também compõe o campo escolar, ou seja, faz parte do processo de socialização no ambiente escolar.

"[...] o choque dos alunos por eu ser tri novo. Sou novo e tenho cara de mais novo ainda né. Daí, aparece lá né, um guri que éo professor. Os mais velhos me respeitam muito, e falam: a tu tem a idade do meu filho e já tá aqui. E os mais novos já querem te tirar pra parceiro, mas não é isso, aqui eu sou teu professor. [...] Mas vendo hoje assim, acho que eu consigo não ter problema de dominar a turma, me respeitam." (Entrevista professor Júlio)

De acordo com Carvalho (1996, p.50):

Uma outra categoria de agentes de socialização durante as experiências de prática pedagógica, frequentemente apresentados como os mais importantes, são os alunos: por um lado eles são a principal fonte do sentimento do sucesso ou de insucesso do estudante-professor, por outro lado, a sua força socializadora alicerça-se nas questões de controle e de manipulação da classe [...].

O mesmo entrevistado relatou sobre sua recente participação em uma greve de professores estaduais e destacou o não cumprimento a direitos como pagamento de piso salarial e excesso de carga horária. Argumentou ainda, que sua participação no movimento grevista guardava coerência com sua postura diante 
dos alunos, de quem cobra uma posição correta e digna como cidadãos, além da importância de lutar por uma educação pública de qualidade.

"Como que eu vou chegar na escola e vou dizer pros meus alunos cumprir as leis, sendo que o meu governador nem me paga, nem cumpre uma lei. Não investe em educação, [que] é outro não cumprimento. No Estado, tinha que ser investido 35\% em educação e ele investe 27\%, não cumpre a lei. Não cumpre a lei do piso, não cumpre a lei da hora-atividade, que éo professor dar 13 horas. Das 20 horas ele dá 13 e as outras 7 é planejamento. Seja na escola, seja nas reunióes. É garantido em lei também, [e] que não é cumprida. Até no meu caso, ele é cumprido, mas a grande maioria não é né." (Entrevista professor Júlio)

A posição assumida pelo professor Júlio, na escola, possivelmente, seja resultado da sua participação no movimento estudantil como um processo de formação política, que não está presente no currículo formal. As referências aos grupos de pesquisa e ações do movimento estudantil são recorrentes nas entrevistas de Júlio e Tiago. No caso do primeiro, sua participação em um grupo de pesquisa é muito valorizada como parte do seu processo formativo e, complementa o entrevistado:

"[...] e também do movimento estudantil, que eu acho que é até o principal, assim da minh a formação, que é um fato que claro nem todo mundo tem acesso, todo mundo tem acordo, mas que são espaços além dos espaços formal que a gente tem aqui né, a gente debate coisas que a gente não debate em aula. Começa a abrir a visão, a enxergar mais a totalidade do curso." (Entrevista professor Júlio)

Para Tiago, que também militou no movimento estudantil, a participação em grupos de pesquisa e projetos de extensão foi citada como parte importante de um processo formativo, combinada à intensa atividade no Diretório Acadêmico, conforme descrita a seguir:

"Me convidaram pra participar, e eu comecei a conbecer tudo. Organizei... a primeira semana acadêmica que eu participei, já foi organizando em 2007, a gente tinh a bastante grupos de estudo, a gente estudava muito, muito, muito e tinh a muito uma questão de trabalho coletivo assim. Isso me deu muita vontade de continuar, porque é uma coisa totalmente diferente do que eu tinha vivido até então, que éo cada um por si." (Entrevista professor Tiago)

O legado do movimento estudantil para o professor Júlio é expresso na seguinte afirmação: "eu levei essa questão da luta por uma sociedade mais justa né, uma sociedade igualitária”.

O que se apreende, das entrevistas de Tiago e Júlio, é que a combinação entre extensão, pesquisa e militância no movimento estudantil, tiveram uma grande relevância em seu percurso formativo, deixando marcas identitárias que estão presentes na forma de atuarem como professores.

\section{CONSTRUÇÃo DO HABITUS E O PROCESSO DE SOCIALIZAÇÃO PROFISSIONAL}

O habitus professoral (Silva, 2005) é construído no início da profissão, ou seja, são os “jeitos de fazer” que o professor vai adquirindo com a prática, e dessa maneira identificam o que funciona e o que não funciona. Por outro lado, não seria falso afirmar que, ao longo do processo de escolarização, o convívio com os professores permite que os escolares apreendam formas de "ser professor" que, de certo modo, podem influenciar na incorporação de modos de ser e de agir que serão reproduzidas quando, mais tarde, se virem na condição de professor.

$\mathrm{Na}$ fala do professor Pedro, percebe-se que, no início do processo de docência na escola, confiaram-lhe uma turma que apresentava dificuldades que lhe exigiam novas ações que pudessem criar novas condições para a realização das aulas. Essa situação desafiadora o levou elaborar novas formas de atuar que contribuíram para legitimar seu componente curricular e favorecer sua atuação. Seu relato expressa exatamente a busca por formas de atuar que funcionem, no sentido materialização da aula com algum êxito:

"E até uma das turmas que eu peguei no início, era o $3^{\circ}$ ano, e era um $3^{\circ}$ ano bem problemático, tinham dificuldades de relação entre eles; a turma não era muito participativa e eu tive que ser rígido na avaliação. Tive que propor coisas novas, que eles não estavam acostumados, tive que propor teoria pra eles porque na prática eles não estavam interessados e eu tive que mudar um 
pouco a avaliação deles também, fiz prova pra eles, mas foi uma ideia, uma visão que tu tive logo no início, que eu vi que eu teria que fazer porque senão eles não iriam levar a sério a disciplina, e deu certo. A partir do momento que eu propus que ia ter critério, elespassaram a ver com um pouco mais de seriedade a disciplina." (Entrevista professor Pedro)

A professora Marta, chama atenção para as dificuldades que teve com a avaliação dos alunos. Em seu depoimento ela relata:

"E a principal coisa [com] que eu me preocupei assim, era como fazer avaliação com eles, como eu já tinha comentado antes. Ai eu optei esse ano por não fazer prova, conversei com eles sobre o que seria melhor pra eles. Perguntei: querem prova de Educação Física, 'não, não, 'sora', a gente não quer prova'. Então a gente faz assim, a gente faz um trabalbinho teórico, outro prático e avalio a participação em aula. Também não vale a pena só avaliar, é dificil pensar o quanto o aluno aprendeu, e isso também é difícil, quer dizer, alguns não aprendem nada, outros aprendem muito e ai. Fiz alguns trabalhos teóricos também." (Entrevista professora Marta)

O relato da professora Marta ratifica a possível indecisão dos professores iniciantes frente às práticas avaliativas. Há uma preocupação em avaliar e, ao mesmo tempo, a dificuldade de escolher métodos ou elaborar instrumentos e práticas que possam responder, adequadamente, a essa necessidade.

O planejamento e a seleção do conteúdo das aulas também são pontos delicados no início da carreira profissional podendo levá-los a usar ferramentas conhecidas conferindo-lhes maior segurança em suas aulas. O professor Júlio optou por começar com os esportes, conteúdo que mais dominava, na tentativa de ganhar a confiança e o respeito dos alunos, mostrando que ele realmente tinha conhecimento do conteúdo que iria trabalhar.

"Então, no início foi bem difícil, até eu não conseguia planejar né o que eu ia fazer, então eu, como é de praxe, assim eu acho, eu comecei pelos esportes, que era o que eu mais dominava e o que mais a gente sabe. Querendo ou não era o que eu mais sabia assim." (entrevista professor Júlio)

A organização didática do ensino da Educação Física no currículo escolar, tem sido uma dificuldade enfrentada pelos professores em início de carreira (Gariglio, 2015), o elevado grau de autonomia dos professores na escolha e trato pedagógico com os conteúdos, o processo de avaliação, por vezes, se manifesta na dificuldade em planejar as aulas de Educação Física. Assim, essa decisão de começar pelos esportes, pode integrar um habitus professoral constituído pelo professor, iniciado antes mesmo do ingresso na universidade, ou seja, são crenças e disposições que o indivíduo adquire ao longo da vida, e que vêm somar-se a sua vida profissional.

\section{Considerações Finais}

A partir dos achados da pesquisa constatou-se a importância da inserção em projetos de extensão, grupos de pesquisa e ensino e movimento estudantil durante a realização da graduação para os egressos investigados, que lhes atribuíram grande significado, como sendo uma complementação das disciplinas do currículo.

Pode-se dizer que esses espaços qualificaram a formação desses jovens, amenizando o choque com a realidade encontrada após o término da formação inicial, ao se inserirem no mundo de trabalho. Nas falas dos entrevistados, ficou identificado que esses espaços lhes forneceram subsídios para a atuação na escola contemporânea, auxiliando no enfrentamento de problemas, através da troca de experiências com os colegas.

Por outro lado, é necessário mencionar as dificuldades apontadas pelos investigados no sentido de se consolidarem como professores e conquistarem o reconhecimento do coletivo da escola. As condições desfavoráveis às quais os professores novatos estão expostos podem adquirir algumas características específicas quando se trata do componente curricular Educação Física. Uma situação pouco precisa no currículo de anos iniciais de Ensino Fundamental faz com que esse componente curricular tenha uma condição de atividade recreativa, pouco vinculada a uma área de conhecimento. A forma como os professores entrevistados reagem a isso, no entanto, é variável, não apenas de acordo com o contexto no qual estão inseridos, mas também influenciada pelas diferentes experiências acumuladas durante a graduação. 
A diversidade de experiências e percursos dos investigados permitiu reunir um conjunto de informações valiosas que levaram a uma leitura muito instigante sobre a socialização de professores de Educação Física, particularmente em fase inicial da carreira, muitas delas conflituosas. No entanto, entre tal variedade, foi possível constatar que, durante o trabalho, ocorre a construção do habitus e a compreensão da inserção no campo escolar, dando aporte para a resolução das situações nessa fase de inserção no campo escolar.

Participações em projetos de extensão, grupos de pesquisa, movimento estudantil, constituem-se como importantes espaços formativos durante a graduação, indicando a existência de um currículo vivido, para além de um currículo prescrito. Para além de conhecimentos científicos, pedagógicos e específicos, parece haver espaço para a elaboração de conhecimentos experienciais vinculados aos fazeres docentes e a constituição de uma consciência política como base para uma postura diante de seus pares na escola e diante das turmas com as quais atuam.

Os resultados obtidos durante a pesquisa sugerem que o currículo de formação inicial dos professores investigados está organizado de modo fragmentado, com pouca articulação entre teoria e prática e distanciados da realidade escolar. A participação em espaços extra-curriculares representa a possibilidade de articular diferentes formas de conhecimento, por meio de uma inserção concreta em espaço sociais, com destaque para as escolas.

\section{REFERENCIAS}

Araujo, F. M.; Alves, E. M.; Cruz, M. P. (2009). Algumas reflexões em torno dos conceitos de campo e de habitus na obra de Pierre Bourdieu. Revista Perspectivas da Ciência e Tecnologia, 1(1), 31-40.

Bolívar, A. (2002). Profissão professor: itinerário profissional e a construção da escola. Bauru, SP: EDUSC.

Borges, C. M. F. (2004). O professor da Educação Básica e seus saberes profissionais. Araraquara (SP): JM Editora.

Bourdieu, P. (1983). Gostos de classe e estilos de vida. In: Renato Ortiz (Org.) Questóes de sociologia. pp.82-151. São Paulo: Ática.

Bourdieu, P. (1989). O poder simbólico. Rio de Janeiro: Editora Bertrand.

Bourdieu, P. (1996). Razóes práticas: sobre a teoria da ação. Campinas (SP): Papirus.

Bracht, V.; Silva, M. S. (2005). Intervenção Profissional Durante a Formação Inicial: contradições e possibilidades das experiências docentes precoces em EF. Revista Motrivivência, 17(25), 57-76.

Carreiro da Costa, F. da. (1996). A Formação de Professores: objectivos, conteúdos e estratégias. In: Francisco Carreiro da Costa, Luís Miguel Carvalho, Marcos Onofre, José Diniz e Catalina Pestana. Formação de Professores em EF: concepçôes, investigaçôes, prática. pp.9-36. Lisboa: FMH.

Carvalho, L. M. (1996). A Formação Inicial de Professores Revisitada: contribuições da investigação sobre a socialização dos professores. In: Francisco Carreiro da Costa, Luís Miguel Carvalho, Marcos Onofre, José Diniz e Catalina Pestana. Formação de Professores em EF: concep̧ôes, investigaçôes, prática. pp.37-56. Lisboa: FMH.

Day, C.; Gu, Q. (2012). Professores: vidas nuevas, verdades antiguas. Madrid: Narcea.

Faria, B.; Machado, T.; Brach, V. (2012). A inovação e o desinvestimento pedagógico na Educação Física escolar: uma leitura a partir da teoria do reconhecimento social. Motriz, 8(1), 120-129.

Freitas, M. N. C. (2002). Organização escolar e socialização profissional de professores iniciantes. Cadernos de Pesquisa, $115,155-172$.

Gariglio, J. A. (2015). Dilemas e aprendizagens profissionais de professores iniciantes de educação física. 37ª Reunião Nacional da ANPEd - 04 a 08 de outubro, Universidade Federal de Santa Catarina (UFSC), Florianópolis.

Lago, S. (2011). Configurações dos projetos de extensão e a formação inicial dos acadêmicos do curso de Educação Física Licenciatura do CEFD/UFSM. Trabalho de Conclusão de Curso. Universidade Federal de Santa Maria.

Moita, M. C. (2007). Percursos de formação e de trans-formação. In: A. Nóvoa (Org.). Vidas de professores. 2ed. pp.111-140. Porto: Porto Editora. 
Molina, R. M. K.; Molina Neto, V. (2010). Pesquisar com narrativas docentes. In: Molina Neto, V.; Triviños, A. N. S. A pesquisa qualitativa na educação física: alternativas metodológicas. 3ed. pp.165-176. Porto Alegre: Sulina.

Poupart, J. (2012). A entrevista de tipo qualitativo: considerações epistemológicas, teóricas e metodológicas. In: Poupart, J. y otros. A pesquisa qualitativa: enfoques epistemológicos e metodológicos. Petrópolis, RJ: Vozes.

Silva, M. (2005). O habitus professoral: o objeto dos estudos sobre o ato de ensinar na sala de aula. Revista Brasileira de Educação, 29,152-164.

Silva, M. F. G.; Souza Neto, S. (2011). Os saberes docentes na história de vida do professor de EF. Curitiba: CRV.

Tardif, M. (2002). Saberes docentes e formação profissional. Petrópolis (RJ): Vozes.

Trivinos, A. N. S. (1987). Introdução a pesquisa em ciências sociais: a pesquisa qualitativa em educação. São Paulo: Ática.

\section{Notas}

1 Os nomes usados no texto são fictícios visando preservar a identidade dos colaboradores.

2 O termo "identidade" e utilizado por alguns autores citados nesse estudo, mas não será profundado por não ser um conceito central do trabalho. Fundamentalmente, pensamos identidade como uma construção continua e imbricada ao processo formativo e que implica reconhecer-se e transformar-se por meio das múltiplasinterações vividas ao longo da vida (Moita, 2007). 